\title{
Study on The Methods of Ground Improvement for Widening Expressway on Soft Ground
}

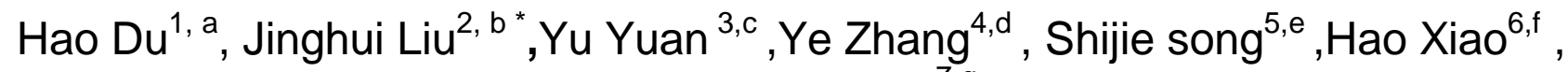 \\ Xiaokang Huang ${ }^{7, g}$ \\ ${ }^{1-7}$ College of Civil Engineering and architecture, China Three Gorges University, P.R.China, \\ a284986314@qq.com, b yangjianxue33@126.com (corresponding author), \\ 670664761@qq.com ${ }^{d} 745431292 @ q q . c o m{ }^{e} 592699425 @ q q . c o m{ }^{f} 429385669$ @qq.com g \\ 1510253700@qq.com
}

Keywords: Soft foundation treatment; Extension project; Differential settlement; Stability Abstract. The highway widening on soft foundation is a new stage of the highway construction, which will be an important issue for country to solve urgently and has to solve at the start of this century. The highway widening on soft foundation inevitably involves the combination of new and old road, the connection of new and old abutments, the differential settlement of new and old embankment and the interaction of new and old embankment. In order to solve the problem of the new subgrade stabilization and differential settlement of new and old subgrade, a suitable soft foundation disposal scheme should be chosen. This paper makes a preliminary discussion about it.

\section{Introduction}

Expressway extension is one of the common methods to deal with traffic volume in rapid growth. However, the problems we meet with expressway extension are more complex than newly built expressway. Such as the new expressway's sedimentation deformation, the impact of new expressway' $\mathrm{s}$ load for the old, the differential settlement (especially in soft soil foundation) between new and old subgrade, the deformation of pavement and so on. These are the problems need to be solved urgently in expressway engineering [1-4]. During the expressway rebuilding and the expansion project on soft soil ground, selecting an appropriate treatment method of foundation and reducing differential settlement of the new and the old embankment, is one of the key technologies of the extension project. There are many methods for soft foundation treatment of expressway. But for reconstruction and extension projects, due to the tight schedule, the restriction of construction yard as well as the maintaining of normal operation of road traffic that has been built, soft foundation treatment has higher demand than newly-built expressway. Fokai Expressway's extension, from Xiebian( K0+000 ) to Sanbao( K46+100 ) , 46.1 kilometers long, has been widened to eight lane standard along two sides or single side of inhered expressway. Because the soft foundation section is too thick and about 16 kilometers, while the quality of the soft soil is inferior, so the soft foundation treatment is engineering's controlled factor.

\section{General Situation of soft soil foundation}

The soft soil is mainly distributed in Pearl River delta, intermountain and depression, including the sludge, mucky soil, mucky sandy loam and mucky sand.

Fokai $(\mathrm{K} 4+000 \sim \mathrm{K} 30+150)$ is located in alluvial plain, where soft soil is widely distributed along the line and very thick, partial missing, and mostly presents grey or charcoal grey. In addition, it includes humus, shell and fine sand layer. According to the available data analysis, the distribution of soft soil is irregular. Two layers soft soil develops in plain area, especially the first layer matters, which is about 14.7 kilometers long and whose thickness changed largely from 0.8 to 25.05 meters. The overburden on the top of the soft soil of the first layer mainly includes artificial filled soil, mild clay and so on. The substratum mainly includes mild clay, sandy soil and rock weathered layer. The second soft soil layer is 
about 4.1-meter long, which is deeply buried and has large thickness variation, and the thickness range is from 0.9 to 15.1 meters. This soft base embankment is the key and difficult point of this extension project.

\section{Comparison and selection of the soft foundation treatment scheme}

At present, the commonest way in extension project which includes composite foundation with pile mesh, plastic drainage plate, composite foundation with wet jetting piles, composite foundation with plain concrete piles, lightweight embankment and so on. In a word, the section of the soft foundation treatment scheme can be divided into three types: drainage consolidation method, composite foundation method and light material method.

Drainage consolidation method can't decrease the total settlement, and main effect of the method is to speed up consolidation of soil. In case of differential settlement, we must set division wall (diaphragm wall) between new and old subgrade. Keeping the load of new splicing foundation completely separated from the effect of the primary one to eliminate the influence of additional settlement, which is a reliable treatment scheme. At the same time, for the new connected subgrade, we can choose the cheap plastic drainage plate to add surcharge preloading. Adapting to the scheme of speeding up the drainage consolidation, which can also prevent additional settlement of old subgrade due to pump pumping dredging. But in this way, the construction period is fairly long, at least about three years.

Composite foundation method, which can decrease differential settlement by strengthening the foundation of widened parts. As for expressway, we usually use traditional method, such as cement injection piles (wet jetting piles) and chemical churning piles to improve bearing capacity of foundation and decrease the differential settlement by forming composite foundation.

Lightweight embankment is a new technology developed in recent years. Using lightweight filler instead of the traditional sand, can decrease the load of soft soil subgrade greatly, thus it can reach the goal of settlement and stability without soft foundation treatment or with little treatment. Light material mainly includes EPS (foam) and light soil mixed bubble, and both of which are applied in domestic engineering. But because the time of the application is too short, as for some problems (such as modulus difference has influence on splicing quality), we also need time to study. Apart from that, because the slightly higher cost and the lack of the basis of large-scale promotion, we will not describe this method in details. Then we will mainly start work in composite foundation method.

\section{Composite Foundation Method}

Composite foundation refers to the part of natural foundation which was treated after foundation processing has been enhanced or replaced, or set in natural ground reinforced materials. Reinforced area is constituted by artificial foundation composed of base (natural soil or improved natural soil) and enhanced body (pile body).Under the load, both natural foundation and enhanced body share the load. Composite foundation reinforcement of different materials has different self-strength and rigidity, its stress mechanism and failure characteristics also different. Upon the analysis of finite element[4-9] which showed that the section's total settlement can be controlled between $10 \sim 30 \mathrm{~cm}$, which has little difference on the existing embankment operation, if the section was treated by composite foundation method that is an applicable method to treat the embankment splicing soft foundation.

Composite foundation treatments come in many forms, the composite foundation treatment methods are used to splice subgrade engineering should meet two conditions: Firstly, its general settlement is small; Secondly, the construction technology is mature and easy to control engineering cost. Therefore, we choose design of cement-mixed piles, plain concrete piles and precast tube piles, which had been widely used in construction of expressway in Guangdong Province, and we discuss above all.

\section{Cement Mixing Piles}

Soil-cement pile composite foundation mainly utilize cement and water in soft clay taking place water mediated reaction and hydration, and the result is that large amount of free water in the soft soil is 
absorbed into water of crystallization and fixed, resulting in a cylinder with a certain intensity, playing the role of consolidation subsoil, which is the more usual composite foundation for soft foundation consolidation method.

But the quality of cement mixing pile is greatly influenced by the factors of construction, which is difficult to control and has limited depth of the processing. From the project information, there will be a bulging pile damage. The experience of Guangdong province shows that deal with a maximum depth of more than $15 \mathrm{~m}$, the pile quality is difficult to control. Because of the strict requirement for the settlement after the expansion, we demand higher standard on the quality of pile body. So when the depth is below $10 \mathrm{~m}$, we recommend the treatment with cement-mixed piles. When the depth is more than $10 \mathrm{~m}$, we need to study a relatively higher intensity, easily controlled quality of pile body material for replacement, increasing its depth of processing and improving the effect of treatment, and combining the generally filling, finally result in cost savings. Cement mixing pile construction method (wet) for the existing embankment with little interference, is suitable for construction of extension project.

\section{Plain Concrete Piles}

CFG pile is the abbreviation of "Cement fly ash gravel pile", means cement-flyash-gravel pile, which is composed of gravel, stone, sand, fly ash with right amount of cement and water mixing, using various forming machine made of variable intensity. Fly ash is added to increase the workability of the mixture and play the role of low-quality cement, increasing the grade of stone chips to improve the gravel. When replaced by sand, piles of fly ash and stone chips which become a plain concrete pile. It belongs to replacement pile, mainly for group piles based or foundation processing to improve bearing capacity of composite foundation. Its construction maximum pile diameter can up to $600 \mathrm{~mm}$, which can through various viscous soil and the powder soil, and through the thickness, slight density, moderate density, and saturated sand formation, but it is difficult to through gravel layer and the bedrock. Thus this pile only works as group pile. Recent two years it has been used widely for expressway soft base processing, which is often a composite foundation method on soft ground section of bridge and culvert structure combined with the sand piles, gradually replace powder-spraying pile.

Plain concrete pile in Guangdong province recently has been more widely applied, having a lot practical experience. Due to the limitation of construction technology of domestic conditions, when the depth exceeds to15 m, piles will suffer from "necking", bulges and other diseases. So when sludge thickness is $10 \sim 15 \mathrm{~m}$, plain concrete piles treatment is recommended. Because this project is quite a stretch of soft foundation depth about $20 \mathrm{~m}$, hence we need to seek a better way of handling.

\section{Precast Tubular Pile}

To this project, some parts of soft foundation are deep (15 to $24 \mathrm{~m})$, and the above two kinds of methods cannot meet the requirements. In this case, the precast tubular pile is a better choice.

A great deal of engineering practice shows that the precast tubular pile has the following advantages and strengths:

(1)Can be industrially made, pile quality is reliable ;

(2) Good durability, high bearing capacity of single pile ;

(3) Design selection is wide and easy to arranged pile. Have strong adaptability to geological conditions with the change of the bearing course at pile end.

(4) Easy to transport lifting, construction preparation time is short, high speed of construction, short construction period, simple and civilized in construction site ;

(5) Good resistance to fight in pile body, strong penetrability ;

(6)Supervision of construction, monitoring the quality of piling easily.

Precast concrete pile composite ground has some features which can deal with a profound depth, fast filling, short construction period and high cost, which is suitable for treating the thickness of the soft soil (or depth) in this project which soft foundation is more than $15 \mathrm{~m}$. Precast concrete pile's diameter 
is flexible, and this project always has sand inclusions, so prefabricated pipe pile diameter should not be so small that can prevent piles fracture under bending when treatment depth is too deep. Pipe pile construction technology for vibration method and static pressure, static pressure construction method is suitable for construction of extension project.

\section{Compare the economic and technological about the methods of Composite foundation}

Table 1 cement injection pile、 plain concrete pile and precast tubular pile in expansion project of the advantages and disadvantages compared

\begin{tabular}{|c|c|c|}
\hline Project & Advantages & Disadvantages \\
\hline Cement Mixing Piles & $\begin{array}{c}\text { low cost, The less } \\
\text { disturbance, Abundant } \\
\text { construction experience, } \\
\text { The settlement is relatively } \\
\text { high, }\end{array}$ & $\begin{array}{l}\text { pile-forming effect is } \\
\text { relatively poor, Quality } \\
\text { management is difficult, } \\
\text { limited treating depth, } \\
\text { generally less than } 10 \mathrm{~m} \mathrm{~m}\end{array}$ \\
\hline Plain Concrete Piles & $\begin{array}{l}\text { The moderate cost, } \\
\text { pile-forming effect is good, } \\
\text { The quality easy to control }\end{array}$ & $\begin{array}{l}\text { Using vibration method } \\
\text { has disturbance, long pipe } \\
\text { auger construction need } \\
\text { large working face }\end{array}$ \\
\hline Precast tubular pile & $\begin{array}{l}\text { factory production, } \\
\text { reliable quality, the treating } \\
\text { depth is highest, } \\
\text { convenience construction, } \\
\text { The subsidence is low, little } \\
\text { old road disturbance }\end{array}$ & The high cost \\
\hline
\end{tabular}

The comparison shows that the three methods have distinguishing features each. In this project, there are many different application conditions for soft foundation treatment, and we should choose methods flexible according to the engineering actual situation for a specific section.

It is worth noting that under the plain concrete pile and pipe pile construction, it will cause certain squeezing effect and excess pore water pressure. Especially when the spacing is small, higher excess pore water pressure has a bad influence on existing embankment. In order to dissipate the excess pore water pressure as soon as possible, we can adopt the method of the pre-fight drainage — - before the pile construction placing the plastic drainage board or bagged manhole to achieve the effect on providing a drainage path.

According to the results of monographic study, in order to achieve the same control standards of settlement, we need to require different spacing when adopt cement injection pile, plain concrete pile and pipe pile. We also need to compare the economy, so this article use a representative cross-section (6m high fill) as an example to analyze and compare its cost. 
Table 2 Comparison of different composite foundation treatment cost

\begin{tabular}{|c|c|c|c|}
\hline $\begin{array}{c}\text { Cost } \\
\text { ten thousand } \\
\text { Yuan/km) }\end{array}$ & \multicolumn{3}{|c|}{ Foundation treatment method } \\
\hline $\begin{array}{c}\text { The depth of } \\
\text { processing ( m ) }\end{array}$ & $\begin{array}{c}\text { Precast tubular } \\
\text { pile }\end{array}$ & $\begin{array}{c}\text { CFG plain concrete } \\
\text { pile }\end{array}$ & Cement mixing pile \\
\hline 8 & 679 & 584 & 497 \\
\hline 10 & 848 & 730 & 621 \\
\hline 12 & 1018 & 876 & 974 \\
\hline 15 & 1643 & 1325 & 1412 \\
\hline 20 & 2651 & 2209 & \\
\hline 25 & 2738 & & \\
\hline 30 & 3286 & & \\
\hline
\end{tabular}

( Remarks : 1. charge unit: prefabricated tubular pile $\mathrm{d}=30 \mathrm{~cm}, 140$ Yuan per meter; concrete cover-plate: 350 Yuan per cubic meters; pile space: 2.0 to 3.0 meters; broken stone hardcore: 50 Yuan per cubic meters; plain concrete pile: 90 Yuan per meter; pile space: 2.0 to 3.0 meters; mixing piles:45 Yuan per meter; sand bed: 30 Yuan per cubic meters; space: 1.3-1.8 meters. )

According to the computational analysis, when meet the settlement demand and when treatment depth is between 10 meters and 15 meters, using cement mixing piles is cheaper. When treatment depth is over 15 meters, using CFG piles is cheaper. But because of the restriction of mechanical and construction process, piling quality is difficult to ensure. Tubular pile' s quality is reliable, and its easy detection and construction, can control subsidence effectively. So the later has more advantages.

\section{Summary}

By analyzing soft soil improvement scheme comparison, we draw the following conclusions:

(1) Suitable for this line expansion road soft foundation treatment method is to compound foundation, doing equal-load preloading during construction period.

(2) Dealing with the soft soil below 10m, it's the most economical method to adopt the cement mixing pile and other flexible pile composite foundation, which is the first choice of high speed highway splicing engineering foundation treatment scheme. But we must strengthen management to guarantee the construction quality about deep mixing pile.

(3) When the depth of soft soil is more than $10 \mathrm{~m}$ and less than $15 \mathrm{~m}$, it's economical to adopt the plain concrete pile scheme. It's also need to strengthen quality of management, adopting rational construction scheme to guarantee the quality.

(4) When the depth of weak soil is equal or more than $15 \mathrm{~m}$, it's economical to adopt prefabricated pipe pile scheme. Besides, the quality is reliable, which is simple to detect, convenient to construct, effective to control settlement. It can also avoid the drawbacks that the strength of soil cement column is low, construction and detection are difficult to control. Prefabricated pipe pile scheme is the best choice to handle soft soil foundation which is deeper than $15 \mathrm{~m}$.

Specific worksite should be closely combined with the specific situation of the project, according to the engineering geological conditions, based on subsidence stability calculation, then we can have flexible choice treatment scheme. 


\section{References}

[1] Zhang Pei. Replacement combined with reinforced study on widening of embankment in soft-soil Foundation treatment with: [D]. Hubei: Wuhan University of technology of road and railway projects, 2008.3

[2] Shunxi Zhou. Application of prestressed pipe pile in Expressway widening engineering technology studies: [D]. Hunan: Changsha University of Science and Technology of road and railway projects, 2007.5

[3] Fu Zhen, Xuan-Cang Wang, Xing-Guang Chen, et al. widen roads differential settlement control after construction [J]. Chang'an University Journal, 2008,28 (5): 10-13

[4] Wang Bin. Connection section of highways subsidence deformation characteristics and Foundation treatment measures of: [D]. Jiangsu: port, coastal and offshore engineering, hohai University, 2004.3

[5] Zhou Heng. Soft Foundation widening project study on design method of high grade Highway: [D]. Jiangsu: geotechnical engineering, Southeast University, 2005.3

[6] Ji-Jun Shi. Numerical analysis of differential settlement of subgrade widening of Expressway: [D]. Jilin Province: Jilin University Road and railway engineering, 2007.4

[7] Zhang Lei. Numerical analysis of widening subgrade deformation: [D]. Shanghai: Shanghai Jiao Tong University geotechnical engineering, 2009.1

[8] Jia Ning. Settlement of soft soil Foundation of Expressway widening project study on characteristics and treatment: [D]. Zhejiang: Zhejiang University, geotechnical engineering, 2004.11

[9] Jian-Wu Gu, Hou Hui. Typical characteristics of soft Foundation in extension project of huning Expressway and treatment measures study: [J]. GEO Foundation, 2005,19 (3): 12-14.

[10] Wen-Zhi Sun, Ai-Guo Jin, Xiao Zhi. Jiang Hu-hang-Yong Expressway widening project [J]. Domestic and foreign road, 2004,24 (4): 34-38

[11] Dong-Fang Yan, Rong-Tang Zhang. Of PCC pile in Highway widening project [J]. Journal of Chinese University, 2007,28 (4): 426-429

[12] Cheng-Fu Chu, Xiao-Dong Liang, Ren-Miao Yan, et al. powder sprayed pile in reinforcement of soft Foundation treatment in Expressway widening project [J]. Journal of Hefei University, 